\title{
CRIANÇAS MIDIÁTICAS: UMA ANÁLISE SOB A SOCIOLOGIA DA INFÂNCIA E SOB A PERSPECTIVA DOS MULTILETRAMENTOS
}

\author{
Fernanda Victória Cruz Adegas* \\ Janaína Nogueira Maia Carvalho**
}

\begin{abstract}
RESUMO: Hodiernamente, percebe-se que as pessoas estão se tornando, gradativamente, mais midiáticas, fato que altera relações sociais e culturais. Desse modo, cabe destacar que a forma de produzir sentidos numa esfera comunicacional também passou por mudanças no que diz respeito aos letramentos mobilizados. Sendo assim, um fator fundamental nessa alteração de paradigmas foi o surgimento das TDICs, as quais passaram a integrar o cotidiano de grande parcela da sociedade. Nesse sentido, nota-se que a atividade de comunicação passou a ser realizada além dos moldes tradicionais, ou seja, a emergência de novas culturas e linguagens transformaram os letramentos, os quais abriram espaços para a proliferação do que se chamou "multiletramentos" (COPE; KALANTZIS, 2006[2000]). Nisso, cita-se que as TDICs ocuparam posição fundamental para a proliferação dos multiletramentos, embora não sejam a única forma, dado que uma história em quadrinhos, por exemplo, também mobiliza várias linguagens e, portanto, vários letramentos. Diante do exposto, o objetivo deste trabalho é analisar, sob o olhar dos Multiletramentos e da Sociologia da Infância (SARMENTO, 2000), a relação entre um público residente numa cultura, paulatinamente, midiática e as possíveis conexões que essas duas áreas podem oferecer para a produção de novas inteligibilidades no assunto. Para tanto, a pesquisa foi realizada por meio de uma ampla revisão bibliográfica a respeito dos principais autores que discorrem sobre os letramentos, multiletramentos e ligações com a educação linguística contemporânea e, também, com autores que estudam a Sociologia da Infância em seu contexto de análise de novas gerações, as quais são embutidas em uma cultura digital. Destarte, conclui-se que é relevante a discussão sobre as temáticas supracitadas, visto que são pontos emergentes na sociedade contemporânea, a qual está sendo formada por indivíduos imersos em universos digitais, marcados por processos de multiletramentos.
\end{abstract}

ABSTRACT: Nowadays, it is noticed that people are gradually becoming more mediatic, a fact that changes social and cultural relations. Thus, it is worth noting that the way of producing meanings in a communicational sphere has also undergone changes with regard to mobilized literacies. Therefore, a fundamental factor in this paradigm shift was the emergence of TDICs, which became part of the daily life of a large portion of society. In this sense, it is noted that the communication activity started to be carried out beyond the traditional molds, that is, the emergence of new cultures and languages transformed literacies, which opened spaces for the proliferation of what was called "multiliteracies" (COPE ; KALANTZIS, 2006[2000]). In this, it is mentioned that TDICs occupied a fundamental position for the proliferation of multiliteracies, although they are not the only form, given that a comic book, for example, also mobilizes several languages and, therefore, several literacies. Given the above, the objective of this work is to analyze, from the perspective of Multiliteracies and Sociology of Childhood (SARMENTO, 2000), the relationship between a public residing in a culture, gradually, media and the possible connections that these two areas can offer to the production of new intelligibility in the subject. To this end, the research was carried out through a broad bibliographic review regarding the main authors who discuss literacy, multiliteracies and links with contemporary linguistic education and also with authors who study the Sociology of Childhood in its context of analysis. of new generations, which are embedded in a digital culture. Thus, it is concluded that the discussion on the aforementioned themes is relevant, as they are emerging points in contemporary society, which is being formed by individuals immersed in digital universes, marked by multiliteracies processes.

PALAVRAS-CHAVE: Multiletramentos; Crianças midiáticas; Sociologia da Infância.

KEYWORDS: Multiliteracies; Media children; Childhood Sociology.

INTERLETRAS, ISSN No 1807-1597. V. 9, Edição número 34. Outubro, 2021/ Março de 2022- p

Dossiê: Educação, infância, diversidade e ensino de língua em contexto complexo. 


\section{INTRODUÇÃO}

Os letramentos podem ser compreendidos como práticas sociais e culturais, as quais possuem a escrita como mediadora. Desse modo, Kleiman (1991) pontua que essa teoria foi, primeiramente, utilizada por estudantes e pesquisadores "como tentativa de separar os estudos sobre o 'impacto social da escrita' (KLEIMAN, 1991) dos estudos sobre a alfabetização, cujas conotações destacam as competências individuais no uso e na prática da escrita" (KLEIMAN, 1995, p. 15-16). Para tanto, nota-se que os Letramentos cumprem a função social de sociabilizar a comunicação entre um grupo de comunicadores, os quais não apenas possuem o mecanismo da decodificação, mas também do envolvimento com a cultura e sociedade em que se situam.

Por conseguinte, é relevante mencionar que o termo Letramento, sendo traduzido do inglês Literacy, foi utilizado no Brasil, inicialmente, pela pesquisadora Mary Kato, em 1986. Assim, nesse momento, o conceito era relacionado a pesquisas a respeito da aquisição inicial da escrita. Dessa maneira, a alfabetização contemplava três pareceres divergentes, a saber: o processo de aquisição do sistema de escrita alfabética; as capacidades individuais e mensuráveis envolvidas nos atos de leitura e de escrita, as quais pode-se chamar de alfabetismos; e o letramento: o "conjunto de práticas sociais ligadas à leitura e à escrita em que os indivíduos se envolvem em seu contexto social" (SOARES, 1998, p. 72).

No entanto, as noções expressas anteriormente só se tornaram mais explicitadas a partir de Street (1984), o qual propôs novos estudos sobre os letramentos, por meio de sua obra Literacy in Theory and Practice. Nesse sentido, o ponto central da contribuição de Street foi a distinção de dois panoramas nos estudos dos letramentos: o autônomo e o ideológico. Acerca do autônomo, elenca-se que a ideia era a de que o letramento influenciaria no desenvolvimento cultural, cognitivo e social dos sujeitos, sendo de modo autônomo e institucionalizado, isto é, "o contato (escolar) com a leitura e a escrita, pela própria natureza da escrita, faria com que o indivíduo aprendesse gradualmente habilidades que o levariam a estágios universais de desenvolvimento (níveis)" (ROJO, 2009, p. 99). Outrossim, sobre o enfoque ideológico, frisa-se que havia a dimensão social dos letramentos, tendo em vista que "os significados específicos que a escrita assume para um grupo social dependem dos contextos e instituições em que ela foi adquirida" (KLEIMAN, 1995, p. 21).

Destarte, pode-se dizer que os letramentos são múltiplos e desenvolvidos, haja vista que são produzidos, construídos e vivenciados em práticas sociais, históricas e culturais. Logo, com o desenvolvimento da sociedade, são necessários novos letramentos, visto que o ser humano tem sido exposto a diversas mudanças, as quais são originárias do surgimento das Tecnologias Digitais da Informação e da Comunicação (TDICs). Quanto a isso, Rojo (2009, p. 105) aponta para "a vertiginosa intensificação e a diversificação da circulação da informação nos meios de comunicação analógicos e digitais", que tem deixado o impresso e o papel à deriva, assim como "a multissemiose ou a multiplicidade de modos de significar que as possibilidades multimidiáticas e hipermidiáticas do texto eletrônico trazem para o ato da leitura", que tem tornado o texto impresso e verbal incapaz INTERLETRAS, ISSN No 1807-1597. V. 9, Edição número 34. Outubro, 2021/ Março de 2022- p

\section{Dossiê: Educação, infância, diversidade e ensino de língua em contexto complexo.}


de situar práticas comunicativas de um público que tem, constantemente, mobilizado as mídias digitais em seu cotidiano. (ROJO, 2009, p. 105). Portanto, não cabe mais falar em Letramentos, mas sim em Multiletramentos, os quais serão exibidos em uma seção posterior.

Diante do exposto, cabe mencionar que o sentido da Sociologia da Infância neste texto, como contribuição de se pensar questões referentes aos 'multiletramentos', reside em compreender a sociedade, a partir do fenômeno social da infância.

Nos referimos ao paradoxo de perceber a peculiaridade com que a infância tem sido trabalhada sociologicamente e, assim, interessa-nos reforçar a ideia de uma renovação contemporânea dos estudos sociológicos da infância, os quais, não obstante, caminham lado a lado com um efeito de invisibilização das crianças como atores sociais. Nisso, afirma-se que esse efeito ainda permanece no domínio do que poderíamos designar como a "ciência normal", pois a expressão "sociologia da infância" se encontra formulada (QVORTRUP, 1991, p. 8). Nessa instância, pontua-se que, sendo antes a consideração da infância como geração sobre a qual os adultos realizam uma transmissão cultural e de "socialização", houve a constituição do objeto de uma das mais importantes obras do início do pensamento sociológico: o uso das mídias para e com a criança.

\section{CONCEPÇÕES DE MULTILETRAMENTOS}

Conforme destacado na primeira seção, à medida que a sociedade evolui são misteres novos letramentos, os quais atendam às demandas comunicativas, culturais e sociais de um determinado público. Assim, em 1996, um grupo de pesquisadores da educação, denominado Grupo Nova Londres, reuniu-se na cidade americana de Nova Londres, com o fito de discutir pontos relacionados à educação contemporânea e, também, sobre os estudos dos letramentos. Nessa perspectiva, cita-se que, devido à multiplicidade da abordagem dos letramentos, surgiu o termo Multiletramentos, o qual abarca os tópicos relativos às novas manifestações comunicativas da sociedade, frente à alta proliferação das TDICs no cotidiano das pessoas.

Diante das discussões elencadas, afirma-se que o Grupo Nova Londres, a partir das discussões empreendidas, publicou o manifesto "Uma pedagogia dos multiletramentos: desenhando futuros sociais"1. Nesse contexto, os pesquisadores explicam sobre a escolha do termo:

Nós decidimos que os resultados de nossas discussões poderiam ser encapsulados em uma palavra - multiletramentos -, palavra que escolhemos para descrever dois importantes argumentos que devemos considerar com a emergente ordem cultural, institucional e global: a multiplicidade de canais e

1 Do inglês "Pedagogy Of Multiliteracies: Designing Social Futures" INTERLETRAS, ISSN N $N^{\circ}$ 1807-1597. V. 9, Edição número 34. Outubro, 2021/ Março de 2022- p

Dossiê: Educação, infância, diversidade e ensino de língua em contexto complexo. 
mídias de comunicação, e a crescente saliência da diversidade cultural e linguística (CAZDEN; COPE; FAIRCLOUGH et al., 1996, p. 63). ${ }^{2}$

Por conseguinte, cabe afirmar que a Pedagogia dos Multiletramentos, proposta pelo Grupo Nova Londres, considera que os indivíduos estão, mormente, com identidades multifacetadas, em virtude de que a todo momento circulam em comunidades diversas e híbridas. Desse modo, a Pedagogia dos Multiletramentos leva em consideração três ponderações, as quais são: a da cidadania, considerando a diversidade cívica; a do trabalho, levando em conta a pluralidade produtiva; e da vida pessoal, contemplando as diversas identidades (KALANTZIS; COPE, 2006[2000]). Para tanto, os autores entendem que o papel da escola é formar indivíduos adaptáveis às diferentes mudanças, comprometidos com sua função cidadã e com uma postura ética em meio às pluralidades.

Postuladas as ideias anteriores, é fulcral destacar que a Pedagogia dos Multiletramentos possui grande potencial para ser trabalhada na educação linguística contemporânea, pois sugere o conceito de design, de maneira que os alunos se apropriem dos textos disponíveis e, com isso, façam o redesign (COPE; KALANTZIS, 2006[2000]). Nesse cenário, a Pedagogia dos Multiletramentos prevê que o aluno passe de um consumidor para um usuário funcional, o qual seja protagonista de seu aprendizado. Quanto a isso, Rojo (2009) pontua que "um dos objetivos principais da escola é possibilitar que seus alunos possam participar das várias práticas sociais que se utilizam da leitura e da escrita (letramentos) na vida da cidade, de maneira ética, crítica e democrática" (ROJO, 2009, p. 107), o que faz com que seja, cada vez mais, necessário teorizar e estudar como as TDICs podem, efetivamente, contribuir com o ensino, bem como sobre o espaço que elas devem ocupar nos currículos. Com base no exposto, Lemke (2010[1998], p. 475) diz que:

\begin{abstract}
Ninguém pode prever as transformações do século XXI durante a revolução tecnológica da informação. Nós certamente não podemos continuar ensinando nossos estudantes apenas os letramentos da metade do século XX, ou simplesmente colocar na frente deles os letramentos mais avançados e diversos de hoje. Precisamos ajudar essa geração a aprender a usar sabiamente os letramentos e esperar que eles se saiam melhor do que nós. (LEMKE, 2010[1998], p. 475).
\end{abstract}

Sendo assim, é pertinente mencionar que os multiletramentos vêm como proposta que busca integrar o conhecimento das TDICs nas atividades de ensino. Nisso, Lemke (2010[1998]) frisa que a tecnologia faz parte da cultura dos indivíduos, os quais a utilizam para diversos fins. Assim, nota-se que estamos diante de um público altamente midiático, o qual mobiliza as TDICs em diversas esferas e, nesse ínterim, é perceptível que os letramentos tradicionais já são ultrapassados, no que diz respeito ao interesse na criação de novos sentidos. Logo, os multiletramentos mostram-se como uma variável favorável ao ensino e à aprendizagem, visto que

\footnotetext{
2 Tradução nossa do original: ": "We decided that the outcomes of our discussions could be encapsulated in one word - multiliteracies - a word we chose to describe two important arguments we might have with the emerging cultural, institutional, and global order: the multiplicity of communications channels and media, and the increasing saliency of cultural and linguistic diversity." INTERLETRAS, ISSN N $N^{\circ}$ 1807-1597. V. 9, Edição número 34. Outubro, 2021/ Março de 2022- $\mathrm{p}$
}

Dossiê: Educação, infância, diversidade e ensino de língua em contexto complexo. 
hoje, qualquer um edita um áudio ou um vídeo em casa, produz animações de boa qualidade, constrói objetos e ambientes tridimensionais, combina-os com textos e imagens paradas, adiciona música e voz e produz trabalhos muito além do que qualquer editora ou estúdio de cinema poderia fazer até alguns anos atrás. (LEMKE, 2010[1998], p. 472).

Com base nas postulações elencadas, é coerente destacar que na concepção dos multiletramentos estão, também, os novos multiletramentos, caracterizados como sendo mais participativos, colaborativos e distribuídos que os letramentos convencionais (LANKSHEAR; KNOBEL, 2007, p. 9). Nessa perspectiva, Lemke (2010[1998]) afirma que os novos letramentos requerem novos valores e práticas, haja vista que as TDICs introduzem uma nova mentalidade nos sujeitos, a qual é chamada de "Mentalidade 2.0", que é análoga à web 2.0 (LEMKE, 2010[1998], p. 461). Em relação à Mentalidade 2.0, cabe afirmar que ela

assume que o mundo contemporâneo é diferente em aspectos importantes do que era há 30 anos atrás e que essa diferença está crescendo. Muito dessa mudança se relaciona ao desenvolvimento de novas tecnologias interconectadas, a novas maneiras de fazer coisas e a novas maneiras de ser que são possibilitadas por essas tecnologias. Mais e mais, o mundo está sendo alterado como resultado de pessoas explorando palpites e "visões" sobre o que pode ser possível, dado o potencial das tecnologias digitais e redes eletrônicas. O mundo está sendo mudado em alguns aspectos absolutamente fundamentais como resultado das pessoas imaginarem e explorarem novas maneiras de se fazer coisas e novas maneiras de ser que se tornam possíveis por causa de novas ferramentas e técnicas, em vez de usarem novas tecnologias para fazer coisas familiares de um modo mais "tecnologizado". (LANKSHEAR; KNOBEL, 2007, p. 10). ${ }^{3}$

Logo, percebe-se que os multiletramentos possuem, como uma de suas finalidades, atender às demandas de indivíduos embutidos num contexto de cultura digital, os quais interagem e criam seus sentidos, por meio da interação com as TDICs. Nesse âmbito, é notório o fato de que o conceito dos multiletramentos se mostra como um tema emergente, sendo capaz de formar além de um usuário com conhecimento técnico, isto é, a pedagogia dos multiletramentos possui o potencial para a formação de sujeitos críticos e conscientes de suas realidades culturais e sociais. Portanto, afirma-se que o trabalho com multiletramentos carrega grande importância para o aproveitamento da cultura digital dos seres humanos, os quais possuem a capacidade de ressignificar conteúdos e realidades.

3 Tradução nossa do original: assumes that the contemporary world is different in important ways from how it was even 30 years ago, and that this difference is growing. Much of this change is related to the development of new internetworked technologies and new ways of doing things and new ways of being that are enabled by these technologies. More and more the world is being changed as a result of people exploring hunches and "visions" of what might be possible given the potential of digital technologies and electronic networks. The world is being changed in some quite fundamental ways as a result of people imagining and exploring new ways of doing things and new ways of being that are made possible by new tools and techniques, rather than using new technologies to do familiar things in more "technologized" ways.

INTERLETRAS, ISSN No 1807-1597. V. 9, Edição número 34. Outubro, 2021/ Março de 2022- p

Dossiê: Educação, infância, diversidade e ensino de língua em contexto complexo. 


\section{CRIANÇAS MIDIÁTICAS E A SOCIOLOGIA DA INFÂNCIA}

O que são crianças midiáticas? Existe infância nesta geração de crianças imersas em um contexto de cultura digital? Ora, a Sociologia da Infância acredita na criança capaz de re/produzir cultura, e é notável perceber que as crianças atuais interagem e criam seus sentidos por meio da interação com as TDICs. Dessa forma, pensando no conceito dos multiletramentos, como meio para a formação de crianças em uma infância para além de um conhecimento técnico, como ilustrado anteriormente, a Pedagogia dos Multiletramentos sublinha um potencial para a formação de sujeitos críticos e conscientes de seu papel cultural e, acima de tudo, social.

Por conseguinte, a Sociologia da Infância registra, sobretudo, nas duas últimas décadas, uma maior expressão, por meio da criação dos seus próprios conceitos, da formulação de teorias e abordagens distintas e da constituição de problemáticas autônomas. Considerando, simultaneamente, as dimensões estruturais e interativas da infância, a Sociologia da Infância desenvolve-se contemporaneamente, em boa parte, como possibilidade de compreensão do que é um dos mais importantes paradoxos atuais, ou seja, nunca, como hoje, as crianças foram objeto de protagonismo e da produção de cultura/s, bem como sobre as questões específicas de estudos em como se dá a geração atual e os usos de linguagens múltiplas para a comunicação.

Ao buscar estudos com um olhar na interpretação das condições de vida das crianças, a Sociologia da Infância insere-se sempre na construção da reflexividade contemporânea sobre a realidade social. É por isso que, ao estudar a infância, não se considera apenas as crianças, mas com a criança: o que ela pensa, sente e produz, com efeito da realidade social que ocupam. Temos, dessa maneira, crianças com diferentes infâncias, sejam ela/s midiáticas ou com identidades multifacetadas, pois estão a todo momento circulando em comunidades diversas como, por exemplo, a internet, ou seja, como as crianças ocupam ou estão utilizando esse instrumento?

Nessa abordagem teórica, as crianças constituem uma porta de entrada fundamental para a compreensão dessa realidade que é, porventura, nova e inesperada no desenvolvimento recente da infância como geração.

O importante aqui é destacar e, ainda, pensar em como está a infância das atuais crianças com as quais convivemos, visto que o novo é inusitado, e os adultos ainda olham para as crianças como se fossem no seu tempo de crianças, esquecendo-se da evolução humana e da revolução da diversidade cultural, na qual vivemos e, esquecem-se de como o avanço midiático cresceu de forma avassaladora.

Conforme o exposto, pontua-se que a Sociologia da Infância ressalta e interroga, ao mesmo tempo, a longa ausência da infância nos estudos sociológicos e do recente desenvolvimento social e cultural da imersão de crianças em jogos, espaços de redes sociais e interações com a mídia de consumo, assim como os chamados 'Youtuber/s'.

INTERLETRAS, ISSN $N^{\circ}$ 1807-1597. V. 9, Edição número 34. Outubro, 2021/ Março de 2022- p

Dossiê: Educação, infância, diversidade e ensino de língua em contexto complexo. 
Assim, a Sociologia da Infância propõe a possibilidade de uma distinção analítica no seu duplo objeto de estudo: as crianças como atores sociais, nos seus mundos de vida, e a infância, como categoria social do tipo geracional, socialmente construída. A infância, então, como fenômeno de estudos, é relativamente independente dos sujeitos empíricos que a integram ou de como ocupam uma posição estrutural. Essa posição é considerada pela relação com as outras categorias geracionais. Desse modo, a infância depende da categoria geracional constituída pelos adultos para a provisão de bens indispensáveis à sobrevivência dos seus membros, e essa dependência tem efeitos na relação assimétrica relativamente ao poder, ao rendimento e ao status social que têm os adultos e as crianças, sendo essa relação transversal (ainda que não independente) das distintas classes sociais (SARMENTO, 2000).

Sarmento (2000), salienta ainda que, por outro lado, o poder de controle dos adultos sobre as crianças está reconhecido e legitimado, não sendo verdadeiro o inverso, o que coloca a infância - independentemente do contexto social ou da conjuntura histórica - numa posição subalterna face à geração adulta. Ao pensarmos em como a criança busca a sociedade, ou em como ela ocupa um papel de protagonista, ilustramos a posição dos multiletramentos, a qual tem relevância no aproveitamento da realidade digital, tanto dos adultos, como também das crianças, e de como tais têm a possibilidade de ressignificar conteúdos e realidades da vida atual que vivem e agem.

As crianças são e devem ser vistas como atores na construção e determinação das suas próprias vidas sociais, das vidas dos que as rodeiam e das sociedades em que vivem. As crianças não são os sujeitos passivos de estruturas e processos sociais. (PROUT \& JAMES, 1990, p. 8-9).

Para Corsaro (2011), as crianças, na sua interação com os adultos, recebem, continuamente, estímulos para a integração social, sob a forma de crenças, valores, conhecimentos, disposições e pautas de conduta, que, em vez de serem passivamente incorporadas em saberes, comportamentos e atitudes, são transformadas, gerando juízos, interpretações e condutas infantis que contribuem para configuração e transformação das formas sociais. Nessa instância, não são apenas os adultos que intervêm junto das crianças, mas as crianças também intervêm junto dos adultos.

Corsaro (2011) ainda registra que as crianças não recebem apenas uma cultura constituída que lhes atribui um lugar e papéis sociais, mas operam transformações nessa cultura, seja sob a forma como a interpretam e integram, seja nos efeitos que nela produzem, a partir das suas próprias práticas (a arte contemporânea, por exemplo, ilustra bem os efeitos das expressões infantis integradas no imaginário coletivo).

Em relação ao mundo midiático, as crianças incorporam uma categoria social: a infância, mas constroem processos de subjetivação no quadro da construção simbólica dos seus mundos de vida, estabelecendo com os adultos interações que as levam a reproduzir as culturas sociais e a recriá-las nas interações de pares. Nessa abordagem, é central o 
conceito de Corsaro (2011) de "reprodução interpretativa": capacidade de interpretação e transformação que as crianças têm da herança cultural transmitida pelos adultos.

Nesse âmbito, as crianças são produtores culturais. Mas, o que isso significa? Significa caracterizar a criança em suas culturas da infância (SARMENTO, 2000), haja vista que elas exprimem os modos diferenciados por meio dos quais interpretam, simbolizam e comunicam as suas percepções do mundo, interagem com outras crianças e com os adultos e desenvolvem a sua ação no espaço público e privado.

Dessa forma, as culturas da infância são geradas nas interações de pares e no contato com os adultos, espelhando as diferenças culturais e são, por isso, declináveis no plural: é de multiculturalidade que se trata, na verdade (SARMENTO, 1997). Entretanto, é importante registrar que as culturas da infância não são a reprodução mais ou menos fiel das culturas adultas; tampouco são culturas adultas diminuídas, imperfeitas ou miniaturizadas. A diferença das culturas da infância decorre do modo específico como as crianças, com características próprias, simbolizam o mundo, nomeadamente pela conjugação que fazem de processos e dimensões como o jogo, a fantasia e a referência face aos outros e a circularidade temporal.

\section{METODOLOGIA}

Tendo em vista o exposto, afirma-se que a metodologia da presente pesquisa possui caráter bibliográfico e analítico, uma vez que foram estudadas e analisadas obras importantes, tanto acerca dos Multiletramentos, quanto da Sociologia da Infância, com o fito de estabelecer conexões, as quais geram novas inteligibilidades nos temas. Nessa instância, pontua-se que, em primeiro momento, buscou-se livros e artigos, os quais abordassem a respeito da teoria dos letramentos, multiletramentos e dos novos multiletramentos. Outrossim, salienta-se que a busca dos materiais acerca dos letramentos levou em consideração livros que tratassem a relação entre multiletramentos e alteração das realidades sociais, no tocante ao uso em massa das TDICs, especialmente com relação aos sujeitos, cada vez mais, midiáticos e inseridos numa cultura digital. Para tanto, foram estudados autores como Roxane Rojo (2009), Cope, Kalantzis (2006[2010]), Lankshear, Knobel (2007), Lemke (2010[1998]) entre outros.

Em segundo momento, foi realizado um estudo acerca da Sociologia da Infância, no contexto de investigar as relações presentes nas crianças do século XXI, no que cerne a indivíduos mobilizadores das mídias digitais em seu cotidiano. Dessa maneira, com base em autores como Sarmento (2000), Corsaro (2011) e Prout \& James (1990), foi realizado um recorte nos textos que dialogavam com as temáticas das novas gerações, bem como com as crianças protagonistas de seus aprendizados, as quais se apropriam das TDICs para a efetivação de suas construções identitárias e intelectuais. Portanto, essa reflexão se faz necessária, uma vez que os estudos sociológicos da infância dialogam com realidades da sociedade contemporânea.

INTERLETRAS, ISSN $N^{\circ}$ 1807-1597. V. 9, Edição número 34. Outubro, 2021/ Março de 2022- p

Dossiê: Educação, infância, diversidade e ensino de língua em contexto complexo. 
Destarte, em um terceiro momento, foi realizada a integração dos estudos dos Multiletramentos com a Sociologia da Infância, com o propósito de estabelecer conexões entre os dois campos de teorias, de forma a analisar as contribuições de ambos e, a partir disso, construir novas perspectivas de análise nas temáticas supramencionadas.

\section{DISCUSSÕES}

Tendo em vista os estudos empreendidos, são necessárias algumas ponderações a respeito das conexões produzidas entre as esferas teóricas estudadas. Sendo assim, afirma-se que a teoria dos Multiletramentos possui a potencialidade para contemplar os seres humanos nascidos em contexto digital, multissemiótico, hipermidiático e multicultural, uma vez que potencializa a competência técnica e tecnológica desses sujeitos em favor de sua aprendizagem em contexto escolar e social. Desse modo, é cabível mencionar que a Pedagogia dos Multiletramentos oferece respaldo para uma educação linguística que vise a formação de sujeitos críticos e transformadores de suas realidades, visto que o conhecimento acerca das TDICs impulsiona a criação de um relacionamento horizontal entre professor e aluno, dado que o processo ocorrido é denominado Paradigma da Aprendizagem Interativa (LEMKE, 2010[1998]). Quanto a isso, elenca-se que o caráter interativo se dá devido à aprendizagem colaborativa do uso das TDICs, propiciando um espaço aberto e dinâmico para o aprendizado.

Analisando a Sociologia da Infância, enquanto campo de investigação emergente, é perceptível que as postulações relacionadas às crianças, no sentido de atribuição de voz e lugar, carregam grande impacto para a formação de usuários plenos de seu papel no aprendizado das multiplicidades dos letramentos. Dessa maneira, nota-se que considerar a identidade midiática das crianças contemporâneas é um ponto crucial para a compreensão dos novos interesses e habilidades que esse grupo vem solidificando, fato que deve ser levado em conta no tocante às práticas pedagógicas de letramentos, as quais devem transpor-se em multiletramentos. Ademais, é pertinente frisar que a visão da Sociologia da Infância, sob a égide de tornar as crianças como membros com voz ativa, pode contribuir, significativamente, para a educação linguística, no âmbito de formar cidadãos críticos, analíticos e conscientes das manifestações comunicativas existentes na sociedade.

Infere-se, portanto, a relevância de as pessoas iniciarem o processo de compreensão no que se refere às novas práticas de letramentos, as quais são marcadas pelo crescimento exponencial das TDICs. Nesse sentido, urge a necessidade da percepção das crianças contemporâneas, as quais já nascem embutidas em uma cultura digital, e que, consequentemente, estão, a todo momento, expostas à tecnologia. Logo, é indubitável que os educadores se apropriem das tecnologias, com o fito de oferecer uma educação plural e que vá ao encontro das potencialidades tecnológicas das crianças inseridas numa sociedade contemporânea, marcada pelo uso ingente das TDICs.

CONSIDERAÇÕES FINAIS

INTERLETRAS, ISSN No 1807-1597. V. 9, Edição número 34. Outubro, 2021/ Março de 2022- p

Dossiê: Educação, infância, diversidade e ensino de língua em contexto complexo. 
Após a realização da presente pesquisa, é mister enfatizar algumas considerações advindas das discussões empreendidas. Assim, é notório o fato de que a busca pelo entendimento dos Multiletramentos com faces na Sociologia da Infância proporcionou uma nova visão a respeito de certos comportamentos das crianças contemporâneas, com relação ao uso e mobilização das práticas da linguagem e dos novos letramentos, que agora são chamados de multiletramentos. Nesse contexto, pontua-se que esse diálogo concede um olhar atento para as características inerentes de uma nova geração, a qual possui as TDICs como parte de sua constituição, bem como os usos de muitas e diversificadas formas de significação, as quais são proporcionadas pelas redes de informação e comunicação como a Internet, por exemplo.

Emerge, também, pensar acerca da percepção das crianças contemporâneas que estão envoltas na cultura digital, sublinhada pela Sociologia da Infância, assim como pela cultura de pares, pois a junção de muitas crianças, em meio a um conjunto de afazeres juntos, torna-se 'cultura' e está, de certa maneira, voltada à mídia. Posto isso, a marca desta pesquisa é salientar a professores para estarem mais próximos das chamadas TDICs e para as questões dos Multiletramentos, lembrando que as crianças, hoje, midiáticas, estão pautadas no uso constante das tecnologias.

\section{REFERÊNCIAS}

CAZDEN, C.; COPE, B.; FAIRCLOUGH, N. et al. A pedagogy of multiliteracies: Designing social futures. Harvard Educational Review, Cambridge, v. 66, n. 1, p. 60-92, 1996.

COPE, B.; KALANTZIS, M. Designs for social futures. In: COPE, B.; KALANTZIS, M. (Eds). Multiliteracies: Literacy Learning and the design of social futures. Nova York: Routledge, 2006[2000], p. 203-234.

COPE, B.; KALANTZIS, M. Multiliteracies: New Literacies, New Learning. In: Pedagogies: An International Journal, [S.1.], v. 4, p. 164-195, 2009.

CORSARO, William. Sociologia da infância. Porto Alegre: Artemed, 2011.

JAMES, A. \& PROUT, A. Construindo e reconstruindo a infância: questões contemporâneas no estudo sociológico da infância (7-34). Londres: 1990.

KLEIMAN, A. B. Modelos de letramento e as práticas de alfabetização na escola. In: (Org.) Os significados do letramento: Uma nova perspectiva sobre a prática social da escrita. Campinas: Mercado de Letras, 1995.

KLEIMAN, A. B. O Letramento na Formação do Professor. Resumo publicado nos Anais do VII Encontro Nacional da ANPOLL. Porto Alegre, 1992. Goiânia, ANPOLL, 1991. INTERLETRAS, ISSN N $N^{o}$ 1807-1597. V. 9, Edição número 34. Outubro, 2021/ Março de 2022- p

Dossiê: Educação, infância, diversidade e ensino de língua em contexto complexo. 
LANKSHEAR, C.; KNOBEL, M. Sampling "the new" in new literacies. In:

(Orgs.) A new literacies sampler: New literacies and digital epistemologies. Nova York: Peter Lang, 2007, p. 1-24.

LEMKE, J. L. Letramento metamidiático: transformando significados e mídias. Trabalhos em Linguística Aplicada, Campinas, v. 49, n. 2, pp. 455-479, 2010[1998].

PROUT, A. (1990). Reconsiderar a nova sociologia da infância: para um estudo multidisciplinar das crianças: Ciclo de Conferências em Sociologia da Infância 2003/2004. Braga, PT: IEC, 2004.

PROUT, A., \& JAMES, A. A new paradigm for the sociology of childhood? Provenance, promise and problems. In A. James \& A. Prout (Eds.), Constructing and reconstructing childhood. London: Falmer Press, 1990.

QVORTRUP, J. Macro-análise da infância. In: CHRISTENSEN, P.; JAMES, A. Investigação com crianças: perspectivas e práticas. Porto, PT: ESEPF, 1991. p. 73-96.

ROJO, R. H. R. (Org.) Escol@ conectad@: os multiletramentos e as TICs. São Paulo: Parábola Editorial, 2013b, p. 13-36.

ROJO, R. H. R. Entre Plataformas, ODAs e Protótipos: Novos multiletramentos em tempos de Web2. In: RAMOS, R. C. G; ARAÚJO, M. S.; TANZI-NETO, A. The ESPecialist: Descrição, Ensino e Aprendizagem, São Paulo, v. 38, n. 1, 2017a, p. 5-25.

ROJO, R. H. R. Letramentos múltiplos, escola e inclusão social. São Paulo: Parábola Editorial, 2009.

ROJO, R. H. R. Novos multiletramentos e protótipos de ensino: Por um Web currículo. In: CORDEIRO, G. S.; BARROS, E. M. D.; GONÇALVES, A. V. (Orgs.). Letramentos, objetos e instrumentos de ensino: gêneros textuais, sequências e gestos didáticos. Campinas: Pontes Editores, 2017b, p. 189-216.

ROJO, R. H. R.; BARBOSA, J. Hipermodernidade, multiletramentos e gêneros discursivos. São Paulo: Parábola Editorial, 2015.

SARMENTO, M. J. (2000). A Infância e o Trabalho: A (Re)Construção Social dos "Ofícios da Criança. In Fórum Sociológico, 3/4 (II Série): 33-48

INTERLETRAS, ISSN N $N^{\circ}$ 1807-1597. V. 9, Edição número 34. Outubro, 2021/ Março de 2022- p

Dossiê: Educação, infância, diversidade e ensino de língua em contexto complexo. 
SARMENTO, M. J.; PINTO, M. (1997). As crianças e a infância: definindo conceitos, delimitando o campo. In M. Pinto e M. J. Sarmento (Coord.), As Crianças: Contextos e Identidades. Braga. Instituto de Estudos da Criança da Universidade do Minho.

SOARES, Magda. Letramento: um tema em três gêneros. Belo Horizonte: Autêntica, 1998.

STREET, B. V. Literacy in Theory and Practice. Nova York: Cambridge University Press, 1984.

*Técnica em Informática pelo Instituto Federal de Educação, Ciência e Tecnologia de Mato Grosso do Sul - Campus Aquidauana, graduanda em Letras - Português / Inglês pela Universidade Federal de Mato Grosso do Sul - Campus de Aquidauana/MS - UFMS/CPAQ. E-mail: fernanda.adegas@ufms.br

**Mestre e Doutora em Educação pela Universidade Católica Dom Bosco (UCDB), Professora Efetiva no Curso de Pedagogia na Universidade Federal de Mato Grosso do Sul - Campus de Aquidauana/MS UFMS/CPAQ, Doutoramento Sanduíche em Sociologia da Infância pela Universidade do Minho Braga/Portugal e Pós-doc em Estudos da Criança na Universidade Católica Dom Bosco (UCDB). E-mail: janaina.maia@ufms.br.https://orcid.org/0000-0002-1528-5665 